\title{
EL ZÓCALO DE LA CIUDAD DE MÉXICO: Un espacio social total
}

\author{
Ángel ACUÑ̃ DELGADO \\ Universidad de Granada, España \\ acuna@ugr.es
}

\section{EL ZÓCALO OF THE CITY OF MEXICO: A total social space}

Resumen: La emblemática plaza del Zócalo de la ciudad de México ha sido un espacio en el que, desde su inicio, las autoridades se ocuparon de hacer visibles el poder político o gubernamental, el religioso o eclesiástico y el económico o mercantil, con la sociedad en el centro. En la actualidad constituye un macro escenario de representación social, donde hay que llegar para hacerse ver y escuchar, donde la afirmación de la identidad nacional no está reñida con el reconocimiento y respeto de la heterogeneidad social y cultural. En base a los datos históricos y al trabajo etnográfico realizado, procuraremos mostrar que se trata de un $<<$ espacio social total >, al constituir un lugar abierto a la participación de toda la gente que lo desee, sin distinción; y un lugar multifuncional que, más allá de la ciudad en donde se encuentra, conecta y hace entendible los diferentes niveles de la cultura mexicana.

Abstract: The emblematic Zocalo square of Mexico City has been a place in which, since its beginnings, the authorities took care to make visible political or governmental power, religious or ecclesiastical and economic or commercial, with the society in the center. Actually it constitutes a macro scenario of social representations, where you have to get to be seen and heard, where the affirmation of national identity isn't incompatible with the recognition and respect of the social and cultural heterogeneity. Based on the historical data and ethnographic work made, we will try to show that this is a $<<$ complete social space $>>$, because is a place of being open to the participation of all the people who wish, without distinction; and it is also a multifunctional place that, beyond the city where is located, connects and makes understandable the different levels of Mexican culture.

Palabras clave: Plaza, Zócalo, Espacio, Cultura, Sociedad

Square, Zocalo, Space, Culture, Society 


\section{Introducción}

"La función crea el órgano". Este antiguo principio axiomático que ha ayudado a entender el papel desempeñado por los distintos componentes de un ser vivo, puede ser aplicado también al ámbito arquitectónico para comprender las necesidades humanas que satisfacen diferentes tipos de construcciones urbanísticas. De entre todas ellas, para dar respuesta a la necesidad que tiene una población de encuentro e interacción social, la plaza ocupa un papel destacado.

Como espacio público dedicado a gran variedad de actividades, la plaza, y especialmente la plaza mayor o principal de una ciudad, ha constituido históricamente el eje central de la vida urbana, el lugar en torno al cual se han ido ubicando los edificios más representativos del poder político, religioso y económico. Lugar que además de servir para el paseo y encuentro ciudadano, suele dar cabida, según el caso, a diversos tipos de espectáculos, exhibiciones, actividades lúdicas, deportivas, mercados provisionales, actos conmemorativos, manifestaciones públicas, etc. Lugar (físico e imaginado) antropológico, definido por la comunicación, interacción social y su carácter histórico y representativo (Augé, 1993). Lugar específico a partir del cual "es posible detectar rasgos distintivos de la urbanidad" (Wildner, 2005:19), por ser los "patios urbanos de las ciudades, que han reflejado como ningún otro recinto la idiosincrasia y la historia de cada ciudad”. (Sánchez del Barrio, 2006: 5).

La variedad de funciones desempeñadas se encuentra en sintonía con la variedad de formas y tamaños. Hay plazas irregulares, propias de la época medieval, con formas trapezoidales, como la plaza del Campo de Siena, con entrantes y salientes, como la plaza de la Jemaa el Fná de Marrakech; y plazas regulares de forma cuadrangular, como la plaza Roja de Moscú, o la de Tiananmen en Pekín (la más grande del mundo con 440.000 m²); circular, como la Cibeles en Madrid o la place de l'Etoile en París, que funcionan a modo de glorieta o rotonda; elíptica, como la plaza de San Pedro de Bernini en Roma; semicircular, como la de España en Sevilla o la Kazansky en San Petersburgo; y alargada, como la de Monterrey. En cualquier caso, dentro de la diversidad, y en atención a las plazas mayores, todas ellas tienen como denominador común "ser una especie de espejo del espíritu forjado a lo largo de la historia de un pueblo, el crisol de la manera de entender la vida urbana,... un microcosmos a la medida de la ciudad y del territorio, físico y mental, que la conforma." (Bonet, 2006:3).

Aunque bien es cierto, como señala Marina (2006: 1), que en los tiempos modernos el móvil, la televisión y los malls o grandes centros comerciales han hecho perder relevancia a la función socializadora de las plazas mayores, aún siguen existiendo desempeñando su papel comunicativo como contrapunto al individualismo.

De entre todas las plazas mayores emblemáticas de las poblaciones en donde se ubican, el Zócalo de la ciudad de México ocupa uno de los primeros lugares. La plaza de la Constitución, llamada así en honor a la Constitución de Cádiz promulgada en 1812, y conocida popularmente como Zócalo, es la principal plaza de esa ciudad, con sus aproximadamente $46.800 \mathrm{~m}^{2}$ (195 m por $240 \mathrm{~m}$ ). Localizada en el Centro Histórico, delegación Cuauhtémoc, fue erigida por los conquistadores españoles sobre el centro político religioso de Tenochtitlan, capital de los mexicas. En el transcurso de los 500 años de historia ha presenciado importantes acontecimientos, acogido numerosas manifestaciones sociales y experimentado significativos cambios en su morfología y edificación circundante, conservando en la actualidad una fisonomía que data de los años 60 del siglo XX.

Teniendo en cuenta su importancia histórica, social y cultural, procuraremos mostrar aquí cómo la plaza del Zócalo de la ciudad de México constituye un $<<$ espacio social total $>>1$, al considerar que se trata de un lugar abierto a la participación de toda la gente, sin distinción,

1 En sintonía con el concepto de "hecho social total" acuñado por Mauss (1979 [1950]. 
aunque no todos los sectores de la población asistan a ella por igual; y un lugar multifuncional que, más allá incluso de la ciudad en donde se encuentra, conecta y hace entendible factores económicos, sociales, políticos, religiosos e interétnicos de la cultura mexicana.

En tal sentido, nos proponemos responder entre otras a preguntas tales como: ¿cuál es el perfil o perfiles sociodemográficos de las personas que transitan la plaza? ¿qué motivaciones las conducen a ella? ¿qué papel desempeña la plaza en la construcción de identidades colectivas? ¿qué vinculación tiene con el desempeño de actividades económicas? ¿qué papel ocupa en el desarrollo de las relaciones sociales, de las manifestaciones artísticas y del esparcimiento? ¿en qué medida es utilizada como plataforma para la expresión del descontento social, para la afirmación del poder político y ciudadano? ¿como escenario expresivo de libertad, crítica y diversidad religiosa? ¿como espacio de tolerancia y encuentro interétnico y multicultural?

Para responder a estas preguntas, la producción de datos se basó principalmente en el trabajo etnográfico realizado de manera sistemática durante los meses de octubre y noviembre de 2013, mediante sucesivas visitas y estancias distribuidas entre el día y la noche ${ }^{2}$. En todo ese tiempo nos dedicamos a la observación participante y no participante en diferentes puntos dentro de la plaza (estación del metro, mástil de la bandera, paseando por su interior) y en lugares periféricos a la misma (terraza de hoteles, atrio de la Catedral, ruinas del Templo Mayor, final de calle Moneda, soportales de Mercaderes), así como al diálogo informal con los transeúntes (nacionales y extranjeros) y personas que desempeñaban algún papel estable en torno a ella (agentes locales, organilleros, vendedores, predicadores, artesanos, danzantes, boleadores de zapatos). De manera complementaria utilizamos también como fuente de información la que aparece en internet, especialmente Km. Cero. Noticias del Centro Histórico de la Ciudad de México $^{3}$; así como la producción bibliográfica de autores que de alguna manera se han ocupado de ella.

Aclarado el tema objeto de estudio, los objetivos pretendidos y la metodología empleada, ofrecemos a continuación y de manera sintética una mirada a los hechos históricos que la acompañan, para seguidamente responder a las cuestiones planteadas.

\section{Recorrido histórico}

El espacio que hoy ocupa la plaza del Zócalo de la ciudad de México se remonta a la época prehispánica, al ser construida en Tenochtitlan, lugar mítico donde los mexica en su peregrinar vieron la señal indicada por el dios Huitzilopochtli en el punto elegido para fijar su asentamiento: el águila posada sobre el nopal devorando a la serpiente.

Como expresa Sánchez Guevara (2009/2010: 3) la historia de la ciudad de México a partir del Zócalo es "la historia de sus sucesivas destrucciones". Investigaciones arqueológicas (Matos, 2012) constatan que en el periodo mexica ocupaba un espacio abierto junto al Templo Mayor, donde se instalaban mercados periódicos. El propio Hernán Cortés, en una carta dirigida al emperador Carlos I, en octubre de 1520, dice lo siguiente:

"Tiene esta ciudad muchas plazas donde hay continuo mercado y trato de comprar y vender. Tiene otra plaza tan grande como dos veces la ciudad de Salamanca, toda cercada de portales alrededor, donde hay cotidianamente arriba de sesenta mil ánimas comprando y vendiendo; donde hay todos géneros de mercadurías que en estas tierras se hallan" (Cfr. Sánchez del Barrio, 2006: 12).

2 Cada jornada empleaba una media de cuatro horas de observación, bien durante la mañana, el medio día, la tarde, la noche o la madrugada, aunque la mayor parte de las franjas horarias observadas fueron las de mayor afluencia de gente, lo que tenía lugar durante la mañana y la tarde.

$3 \mathrm{http} / / /$ www.guiadelcentrohistorico.mx/kmcero (Accedido el 20 de febrero 2014). 
Tras la caída y destrucción de México Tenochtitlan, se preparó la nueva Plaza Mayor en 1524; y las piedras del derruido Templo Mayor y otras edificaciones mexicas fueron empleadas para erigir la Catedral y el Palacio del Virrey (luego Palacio Nacional), reservando el lado oeste para la actividad comercial, que más tarde se convertiría en el Portal de Mercaderes.

La construcción colonial de una plaza cuadrangular al estilo renacentista de la época ${ }^{4}$, refleja la situación del momento, un momento que necesitaba de un espacio para el encuentro entre distintas culturas: indígenas, negros, mestizos, criollos, españoles; un espacio polifónico y polícromo, un espacio "físicamente homogéneo pero heterogéneo en composición étnica, política, sexual,..." (Sánchez Guevara, 2009/2010: 7).

Se inundó en 1629, destruyéndose muchos comercios por la subida del agua que alcanzó los dos metros de altura. La Catedral que inició su construcción al norte de la plaza en 1576 concluyó su obra en 1657. Durante los siglos XVI y XVII el comercio y las festividades fueron sus principales usos. En 1692 fue incendiado el Palacio Virreinal. Y en 1703 inaugurado el Parián, conjunto de tiendas ubicadas en la esquina suroreste usadas como almacén y para la venta de productos llegados de Europa y Asia.

Además de la actividad comercial, las celebraciones festivas, tanto religiosas como civiles, ocuparon un papel destacado, teniendo lugar en ella corridas de toros, mascaradas, funciones de teatro, fuegos de artificio, certámenes literarios. Por los monarcas españoles fallecidos se llevaron a cabo honras fúnebres. Sirvió igualmente como patíbulo, lugar de ajusticiamiento para hacer cumplir públicamente la sentencia de los reos por medio de la horca o la picota. También sirvió para verificar autos de fe de manera multitudinaria. Y como escenario de rebeliones, siendo la primera en 1692, conocida como "motín del hambre". (Ortega, 2013a).

En 1790, tras la proclamación de Rey a Carlos IV un año antes, la plaza fue renovada, vuelta a nivelar y pavimentar, se instaló una fuente en cada esquina, y durante los trabajos se hallaron la Piedra del Sol y una escultura de la diosa Coatlicue. Los comerciantes se trasladaron al nuevo edificio llamado "Mercado Volador" en el lado sureste. Con 64 lámparas para iluminar por la noche, la plaza se convirtió en un espacio público. Años más tarde la Catedral fue separada de la plaza mediante una reja de hierro. Y el 22 de mayo de 1813 el nombre de Plaza Mayor cambió por el de Plaza de la Constitución, en homenaje a la Constitución de Cádiz. (Ortega, 2013b).

En el proceso de Independencia de México (1810-1821) la plaza cobró protagonismo al ser testigo de la entrada triunfal del Ejército Trigarante, encabezado por Agustín de Iturbide, y escenario de la jura de la Independencia.

El 4 y 5 de diciembre de 1826, un grupo de soldados, artesanos y exaltados, encabezados por Lorenzo Zabala y el general José María Lobato arrasaron a los comerciantes del Parián al grito de ¡Muerte a los gachupines!, acabando con la vida de muchos de ellos. En 1843 el presidente Antonio López de Santa Ana demolió el Parián, replegando la actividad comercial hacia los márgenes, al tiempo que proyectó construir en el centro de la plaza un monumento a la Independencia de México, construcción que se quedó tan solo en la base (zócalo), que así se mantuvo durante décadas, dando lugar al nombre popular empleado por la gente que allí se citaba y a la idea de ser la plaza central: el Zócalo ${ }^{5}$.

\footnotetext{
44 Las formas irregulares de las plazas medievales, son superadas por la proporción geométrica y la perspectiva que marca el estilo arquitectónico de las plazas del Renacimiento, plazas a las que se suma el componente simbólico de los edificios monumentales que la rodean como representación jerárquica de los poderes establecidos. (Sánchez del Barrio, 2006: 9).

5 Los nombres oficiales que ha tenido el Zócalo son: Plaza Mayor, Plaza de Armas, Plaza Principal, Plaza del Palacio y Plaza de la Constitución.
} 
En 1866, tiempo del emperador Maximiliano de Habsburgo, experimentó una nueva transformación. La creación de un jardín con senderos, fuentes en cada esquina, la colocación de 72 bancos de hierro y la iluminación con lámparas de gas de hidrógeno, la convirtieron en un lugar especialmente utilizado para pasear, al igual que para comerciar, por los numerosos puestos de mercado instalados en la periferia entre mediados del siglo XIX y principios del XX. Sobre 1880 la compañía de Ferrocarriles del Distrito Federal convirtió parte del Zócalo en estación de tranvía. Las calles del Zócalo fueron asfaltadas en 1891, y en 1894 los tranvías y la iluminación pasaron a funcionar con energía eléctrica.

Durante el Porfiriato (1876-1911) el Zócalo, como otras plazas, fueron utilizadas para las manifestaciones patrióticas del régimen, como la ceremonia del Grito de Independencia y el desfile militar, los días 15 y 16 de septiembre respectivamente. En 1896, el presidente Porfirio Díaz trasladó la emblemática Campana de Dolores a la fachada del Palacio Nacional. Palacio que fue bombardeado entre el nueve y 19 de febrero de 1913, la "Decena Trágica" donde fue derrocado el Presidente Francisco Madero, dañando también al Zócalo. (Ortega, 2013b).

Ya entrado el siglo XX, la plaza apropiada durante tres décadas por el Presidente pasó a ser un espacio público para la libre expresión política, social o cultural. Fue el siglo que más modificaciones arquitectónicas experimentó, en consonancia con los cambios sociales y políticos. A partir de 1915 y en un periodo de aproximadamente 50 años, se produjeron unas 15 intervenciones que modificaron su fisonomía. Por esa época (entre 1940-1948) según García Canclini (1998: 21; cfr. Wildner, 2005: 101), "el centro debía manifestarse como 'ombligo histórico de la nación', y de ese modo representar visualmente la unidad nacional". En 1958 fueron retirados los jardines dejando la plaza como una explanada abierta con su austero aspecto actual, aunque sin las planchas del pavimento, colocadas años más tarde, y la impresionante asta bandera ${ }^{6}$ en el centro. Entre 1967 y 1970 se construyó el metro con una estación para la entrada y salida en la propia plaza.

Lugar de expresión popular, en 1968 los estudiantes universitarios se manifestaron masivamente en el Zócalo en tres ocasiones, siendo desalojados por los militares el 27 de agosto, pero tras la masacre estudiantil sufrida el dos de octubre en la plaza de Tlatelolco, pasaron 14 años sin que acogiera ningún movimiento de protesta. No obstante, a fin de despertar o mantener el sentimiento ciudadano de lealtad a la Patria, cada 15 de septiembre se sigue celebrando el tradicional "Grito de Dolores" con proclamas de "Viva México", en conmemoración del comienzo de la Guerra de Independencia. Asimismo, a diario se procede regularmente a la ceremonia de izada y arrida de la bandera a las 06:00 y 18:00 horas respectivamente, mientras las actividades que se lleven a cabo en la plaza lo permitan?

Como consecuencia de los catastróficos terremotos ocurridos el 19 y 20 de septiembre de 1985, el Zócalo se convirtió en espontáneo lugar de reunión donde acudir para encontrar protección, y posteriormente en centro de acopio y distribución de productos (alimentos, ropa, medicinas) para los damnificados. Circunstancia que volvió a producirse con motivo del devastador tsunami sufrido en las costas de Oaxaca y Guerrero el 20 de julio de 2013.

Ya en el siglo XXI, el Zócalo es contemplado por las autoridades dentro de los planes que se proyectan sobre el Centro Histórico de la ciudad, en donde preocupa el deterioro del mobiliario urbano, la suciedad, la acumulación de basura, el ruido, la inseguridad ciudadana, las manifestaciones ${ }^{8}$, la congestión del tráfico y la polución. Constituye asimismo un escenario utilizado para las más diversas formas de expresión y representación (día del

$6 \mathrm{El}$ asta mide 50 metros de altura y la bandera pesa 50 kilos, con unas dimensiones de 24 x 14.3 metros.

7 Durante la Feria Internacional del Libro, por ejemplo, debido a que el espacio está ocupado por numerosas casetas de exposición, la bandera permanece desplegada todo el tiempo, sin que se ice ni arríe cada día.

8 La masiva presencia policial y militar para evitar a veces manifestaciones no autorizadas ofrece también la imagen del papel represor del Estado. 
Niño, día de Muertos, día del Libro, conciertos, teatro, cine, exposiciones, etc.), en donde, por su dimensión, están presentes también la consecución de récords ${ }^{9}$.

El Zócalo, en definitiva, ha ido cambiado su fisonomía a lo largo de la historia reactualizándose permanentemente con los nuevos actores que pasan por ella. Sigue siendo un lugar emblemático para celebrar a los héroes, para exaltar el poder político, pero desde 1968 ha sido tomado gradualmente por la sociedad para protestar y manifestarse, para entretenerse y disfrutar de actividades culturales, para que sectores marginales, como gays y lesbianas, reivindiquen sus derechos, para gestionar la solidaridad ciudadana ante las catástrofes. Emplazado junto a lo que en su día fue el Templo Mayor, centro ceremonial para los mexicas allí asentados, plasma de manera sobresaliente la historia de la ciudad e incluso del país, entendido como un lugar para todos y para casi todo.

\section{Un lugar de condensación multifuncional}

Comencemos por caracterizarlo en base a los elementos principales que lo estructuran. $\mathrm{El}<<$ espacio >> es uno de ellos y, como ya dijimos, es prácticamente cuadrangular, con unas dimensiones aproximadas de $46.800 \mathrm{~m}^{2}$ en pleno Centro Histórico. Está rodeado al norte por la Catedral Metropolitana, al este por el Palacio Nacional, al sur por el antiguo Palacio del Ayuntamiento y el Edificio de Gobierno, y al oeste por el Portal de Mercaderes y demás edificios comerciales, administrativos y hoteles. Dentro de la misma plaza se encuentra la estación Zócalo de la línea 2 del Metro, y en la esquina noreste el Museo del Templo Mayor.

El área periférica se haya convertida en estos momentos en una glorieta que permite la circulación automovilística a su alrededor, dejando la zona central, pavimentada con grandes planchas de concreto, sin decorado o mobiliario urbanístico alguno, vacía por completo, con la excepción del asta bandera situada en una posición central, aunque no exactamente en el centro geométrico, alineada, eso sí, con la puerta del Palacio Nacional, la puerta principal de la Catedral y la Avda. 20 de Noviembre. Espacio vacío que continuamente permite modificar temporalmente su fisonomía por el montaje de carpas, expositores, escenarios, graderíos, piezas escultóricas, atracciones de feria, etc., para el desarrollo de numerosas actividades.

En cuanto al $<<$ tiempo $>>$ de ocupación/desocupación, de ordinario el Zócalo se va llenando de gente a medida que avanza la mañana, hasta el medio día que se desocupa por momentos en las horas más calurosas y habituales para comer. A partir de ahí, volverá a llenarse progresivamente en la tarde, hasta que cae la noche y el público se retira. Pasadas las 12:00 de la noche y ya entrada la madrugada, la explanada queda prácticamente vacía, para que el equipo de limpieza haga su trabajo al alba.

Con los primeros rayos de sol y la plaza ya limpia, a las seis de la mañana la ceremonia de izada de bandera, protagonizada por un grupo de militares, inaugura el despertar del día. Acto seguido, son quienes desempeñan en ella algún oficio (taxistas, ciclotaxistas, policías, boleadores, organilleros, vendedores ambulantes, empleados de tiendas, etc.) los siguientes en llegar, junto con algunos que otros madrugadores visitantes. La solemne arriada de bandera a las seis de la tarde será a su vez uno de los momentos que más gente concentre para presenciarla, a la vez que punto de inflexión para que, una vez concluida, comience el voluntario desalojo. En la oscuridad de la noche, con la lejana iluminación de los edificios circundantes, quedan, no obstante, algunos paseantes contemplando el panorama nocturno, parejas de enamorados, o vendedores de artilugios voladores fosforescentes.

Con motivo de la realización de eventos extraordinarios (conciertos, espectáculos, mí-

9 En 2007 unas 20.000 personas desnudas fueron fotografiadas por Spencer Tunick. En 200939.879 personas se besaron al mismo tiempo dentro de la plancha. En 2012 unas 210.000 personas asistieron allí al concierto de Justin Bieber; y en el mismo año, unas 200.000 asistieron al de Paul McCartney. (http://es.wikipedia.org/wiki/ Plaza_de_la_Constituci\%C3\%B3n_(Ciudad_de_M\%C3\%A9xico) (Accedido el 22 de febrero 2015). 
tines, días especiales...) la afluencia de gente discurrirá, obviamente, de acuerdo al horario establecido en cada caso.

$\mathrm{La}<<$ gente >> que acude al Zócalo es heterogénea en cuanto a edad, sexo, aspecto físico, nacionalidad, etnia, formación o clase social. En solitario, en pareja o en grupo más o menos numerosos, podemos ver niños, jóvenes, adultos y mayores; hombres y mujeres; mexicanos y extranjeros de diferentes países; criollos, mestizos, negros e indígenas; residentes del DF y turistas; personas que por su aspecto sugieren ser intelectuales, deportistas, aventureros o profesionales de distintos oficios; así como económicamente más o menos solventes. En relación con esto último, por el hecho de tratarse de un espacio público y el uso que se hace de él, el perfil sociodemográfico que más abunda da la impresión de ser de clase media y baja; media para quienes de manera eventual, esporádica o regular lo visita como transeúnte, y media baja y baja para la mayor parte de quienes de manera más o menos permanente intentan ganarse la vida allí mediante el desempeño de alguna tarea.

Las $<<$ actividades $>>$ que se desarrollan en su interior responde a las diferentes motivaciones que acompañan a quienes por ella transitan, siendo también la diversidad lo que mejor las define. De ese modo encontramos quienes desempeñan algún tipo de actividad laboral relacionada con la seguridad, el transporte, la higiene, la salud, el entretenimiento o el comercio: policías, militares, taxistas, encargados de limpieza, boleadores, organilleros, vendedores ambulantes, payasos, sanadores, masajistas; proselitistas de carácter religioso que expresan sus inquietudes y creencias solos o acompañados: predicadores católicos, evangélicos, grupos de Hare Crishna; representantes de partidos políticos pronunciando mítines; gremios o sectores sociales que manifiestan su protestas y reivindicaciones con acampadas o sin ellas, con discursos y pancartas; procesiones religiosas; desfiles militares; conmemoraciones, pronunciamientos y actos gubernamentales; celebraciones anuales con motivo del día del Niño, de la Mujer, del Libro, de Muertos, etc.; exposiciones fotográficas, pictóricas, arqueológicas; muestras de arte y artesanía; conciertos musicales folk, clásicos, pop, etc.; interpretación de danzas de concheros; de break dance; representaciones teatrales; actividades deportivas que transforman el escenario en un campo de fútbol, una pista de patinaje, o el punto de salida y llegada de maratones populares; recogida y almacenamiento de víveres en apoyo a desastres; o sencillamente el hecho de pasear para distraerse, conversar, reflexionar, contemplar o fotografiar el paisaje y el paisanaje. Un espacio en definitiva en el que cabe todo tipo de gente y en el que hay tiempo para casi todo tipo de actividades.

Lo que no tiene cabida es lo no autorizado, lo que a juicio de las autoridades atenta $o$ amenaza el orden o el bienestar público, prohibiéndose como medida preventiva. La $<<$ normativa > para el uso y disfrute de la plaza, encontramos, sin embargo, que resulta bastante tolerante, en la medida que, pese al fuerte dispositivo policial y a veces militar desplegado por ella, lo que da la impresión de estar sujeta a una severa represión, lo cierto es que, por lo general, cualquiera puede ocuparlo para vender las más variadas mercancías, o expresar libremente a diario su ideología religiosa, filosófica, política o de otro tipo, por megafonía si así lo quiere. La prohibición y control estatal se orienta por lo común hacia ciertas manifestaciones o acampadas multitudinarias, con frecuencia de carácter obrero, que estiman pueden dar lugar a altercados de orden público, aunque se propongan pacíficas, como ocurrió con la protesta de maestros a lo largo de 2013, acampados finalmente en la plaza de la República junto al monumento a la Revolución. $\mathrm{O}$, de otro modo, a impedir la saturación o excesiva apropiación del espacio, como ocurre con la danza de los concheros, antes interpretada por numerosas agrupaciones en diversos puntos dentro de la plaza, y ahora sólo permitida en dos de sus esquinas dos días a la semana, según la versión de algunos agentes de policía, por haberse incrementado en exceso el número de grupos y acaparar así demasiado terreno:

"Antes sí que había muchos grupos aquí en la plaza y la gente se paraba a ver, [...] es tradicional y gusta escucharlos y verlos pero cuando son tantos no se 
puede pasear tranquilo y llega a ser molesto, [...] ahorita no se permite, solo por el lado de allá (señala la esquina sureste) se ponen algunos días" (Pedro, policía federal).

Por sus características, el Zócalo reúne los rasgos distintivos que lo definen como "lugar" (Augé, 1993): es histórico, relacional e identificatorio. Está construido por recuerdos de acontecimientos que hablan del pasado, de un pasado precolombino, colonial y poscolonial, por el que han transitado numerosos personajes y sucedido innumerables episodios, cuyas huellas, si bien han sido borradas sucesivamente del espacio material por el cambio de ocupantes, han quedado registradas en la literatura. De manera regular ha sido utilizado como lugar de encuentro para realizar infinidad de prácticas, resignificadas con el paso del tiempo; un lugar de relación e interacción ciudadana, reflejo de la vida cotidiana, donde se ha hecho valer igualmente lo que más inquieta y conmueve en cada época. Espacio asimismo emblemático, catalizador de identidades, en el que uno se reconoce vinculado al grupo de referencia, a su tierra, a su tiempo, a su historia, a los suyos. "Yo vivo en la Delegación de Xochimilco y me gusta venir al Zócalo, hay espectáculos de continuo, gratis, te sientes bien aquí, siempre aprendes cosas nuevas, lo que hacemos en México", dice Miguel Ángel, mexicano de unos 40 años, usuario habitual del Zócalo.

En relación con las Plazas Mayores, Lefebvre (1974; cfr. Velasco, 2007: 413) llama la atención sobre "la producción social del espacio", refiriéndose a cómo éstos espacios privilegiados para la puesta en escena de los poderes públicos quedan marcados por la arquitectura de cada época. Y más recientemente, Arango (2002), en relación al Zócalo pone énfasis en dos conceptos claves para su comprensión: el de espacio público y el de sociedad civil. El primero constituido por "el escenario donde desplegar los dramas sociales y se manifiesta y representan las tramas de la vida cotidiana", donde se escenifican "los imaginarios y campos sociales" (Ibid.:12). Y el segundo sujeto a una gran heterogeneidad, dialogante siempre con los espacios llenos de historia y capital político social. En tal sentido, la plaza en cuestión, durante al menos el siglo XX y XXI ha sido testigo tanto de actitudes caudillistas, como de otras diametralmente opuestas marcadas por la diversidad y la pluralidad.

Actitudes que podemos también encontrar representadas en otros lugares de América y del resto del mundo, porque todo espacio urbano posee zonas de contacto donde se entrecruzan moralidades contrastantes y aún contradictorias, mentalidades que, por diversas que sean, forman parte del mismo universo y han de convivir (Arantes, 1994). Estas zonas o territorios de contacto, en las grandes metrópolis generan poderosos impactos y fuertes repercusiones socioculturales, que, según Lacarrieu (2003), en relación a Buenos Aires, suelen estar asociados con lugares patrimoniales y sirven como anclajes urbanos de la denominada "cuestión social". Lugares amplios que hacen posible la concentración popular, y son utilizados con regularidad para celebrar rituales conmemorativos, mediante la exaltación y el reconocimiento de una situación peculiar, circunstancia que repetida año tras año, en palabras de Nieburg (2003), facilita la "rutinización del carisma", como ocurrió también en Buenos Aires, el 17 de octubre en Plaza de Mayo, desde 1945 a 1955, con motivo de la celebración del Día de la Lealtad Peronista, símbolo del movimiento obrero argentino, en recuerdo a la gran movilización obrera y sindical que en ese día de 1945 tuvo lugar en Argentina exigiendo la liberación del entonces coronel Juan Domingo Perón, derrocado más adelante en 1955. Conmemoración que sigue vigente en la actualidad, aunque la celebridad internacional del emblemático lugar se debe sobre todo, al incansable testimonio de unas madres, que desde 1977 se vinieron reuniendo en Plaza de Mayo frente a la Casa Rosada, sede de la Presidencia del Gobierno, para manifestarse y reclamar el regreso de sus seres queridos desaparecidos en la dictadura de Videla.

Como todo lugar, en donde el espacio ha de ir inevitablemente unido al tiempo para que cobre sentido, el Zócalo es un lugar "polisémico" y "polifónico” (Sánchez Guevara, 
2009/2010: 15), en la medida que, identificado con quienes lo ocupan, ha ido cambiando de sentido en lo físico y en lo social; y a través de él se manifiestan múltiples voces con significados diversos. El fenómeno de ocupar plazas viene de lejos, se ha realizado de distintas maneras y por diferentes motivos. En la actualidad podemos observar, como señala Stavridis (2012), en relación con la ocupación de ciertos espacios públicos a partir de la crisis socioeconómica de 2008, que la plaza Syntagma de Atenas, en el caso griego, sirvió para catalizar sentimientos compartidos de pertenencia a un movimiento de protesta, y para hacer surgir nuevas formas de subjetivación política. De semejante forma, aunque con mayor eco, al papel ejercido por la plaza de la Puerta del Sol en Madrid, y otras muchas plazas de España, que hicieron surgir el Movimiento $15 \mathrm{M}$. Movimiento que reivindica una democracia deliberativa y participativa, con una ciudadanía vigilante e informada (Ovejero, 2013). Movimiento exportado a otros muchos países que se fragua en las plazas, y de donde salen consignas como: "Sin casa, sin curro, sin pensión, sin miedo", "iIndígnate!", "Nuestros sueños no caben en vuestras urnas", "Toma la plaza".

El Zócalo es a su vez un lugar "tópico" para quienes, por gusto o por exigencias de su modo de vida, lo transitan a diario y se han llegado a familiarizar con él hasta convertirlo en algo normal y propio. Y "heterotópico" (Foucault, 1967) para quienes constituye un lugar paralelo a los más comunes, frecuentado sólo a veces por motivos puntuales que se pueden repetir con mayor o menor frecuencia. En tal sentido, la percepción de Rafael, bolero que lleva años limpiando zapatos en el Zócalo y su entorno, es diferente a la de Verónica, que acude a él de modo esporádico cuando se presentan actuaciones musicales. Asimismo es un lugar propicio para albergar "cronotopos", es decir, acontecimientos que entrelazan espacio y tiempo en una única dimensión (Velasco, 2007: 367), que desempeñan una función figurativa y se celebran regularmente con cierta periodicidad. Tales acontecimientos (día de la Independencia, día de Muertos) se encuentran marcados en el calendario y constituyen una forma más de medir o situarse en el tiempo. "[...] el 16 de septiembre, día de la Independencia (de México), ese día no falto, [...] es emocionante ver el desfile (en el Zócalo), escuchar el himno nacional, el grito de dolores, [...]", dice Jesús, mexicano de unos 60 años.

Pero si bien el Zócalo es un lugar central en la ciudad de México y un referente fundamental para todo el país, con todos los atributos mencionados (tópico, heterotópico, cronotópico, polisémico, polifónico), podemos también observarlo como un "no lugar" (Augé, 1993), producto de la sobremodernidad, como un espacio utilizado exclusivamente para la circulación de vehículos que transportan personas y mercancías, como ocurre en la glorieta que lo circunda, dedicada al tráfico automovilístico. De igual modo dejaría de ser concebido como lugar (de acuerdo a las características ya mencionadas) para todas aquellas personas que pasen por él con la exclusiva finalidad de tomar el metro o un taxi, por ejemplo, sin que le sugiera o le incite el más mínimo interés histórico, relacional o identitario.

Lugar y no lugar al mismo tiempo en razón al uso y a la concepción que se tenga de él. Pero al margen de su uso y concepción como mero espacio circulatorio y de paso, centremos la atención en las razones por las que ha de observarse como un LUGAR con mayúsculas.

La primera de ellas tiene que ver con la $<<$ construcción de identidades colectivas $>>$, con el refuerzo de la conciencia nacional a través de un espacio histórico, localizado casualmente en el centro de la capital, que para muchos es el "ombligo del país" o "su corazón". Wildner (2005:274) lo define como "lugar de condensación" de significados diversos, donde se "representan ofertas de identificación" y cada cual construye la suya a su manera, en función de su biografía personal, de su saber y de su historia; un espacio para construir identidades a la carta, por distintas vías, y con marcadas distinciones, aunque una de ellas sobresalga de manera predominante por su factor emocional: el orgullo de la mexicanidad. "[...] ese día (el de la Independencia de México) ver hondear la bandera (en la plaza) y escuchar al tiempo el himno nacional hace que se me salten las lágrimas" (Jesús, mexicano de unos 60 años). 
"La piel se pone chinita", dicen algunos al referirse a la arriada de bandera producida diariamente al caer la tarde. En la mañana de todos los lunes, un grupo escolar protagoniza en la explanada una ceremonia en honor a la bandera con la participación del alumnado y profesorado, al igual que en todas las plazas mayores de las distintas ciudades del país. De ese modo el poder estatal institucionaliza una serie de rituales, de gestos simbólicos con los que mantener la cohesión comunitaria, que la propia gente hace suyos y promociona. La gran explanada con el asta bandera por el centro como único elemento sobresaliente, conforma un espacio propicio para las manifestaciones de las fuerzas políticas y ciudadanas del país. El Estado se reserva un buen número de fechas conmemorativas para la exaltación de la Patria: el 5 de febrero por la Constitución; el 5 de mayo por la victoria sobre los franceses en 1862; el 15 y 16 de septiembre por la Independencia; el 20 de noviembre por la Revolución Mexicana; etc. A lo que hay que añadir los mítines masivos de partidos políticos (PRI, PRD, ...) por motivos electorales, con concentraciones de más de 100.000 asistentes.

Pero en contraste con la <<afirmación del poder estatal y de las fuerzas políticas $>>$, el Zócalo es desde los años $60<<$ escenario de manifestaciones por la que se expresa el descontento social, se reivindican derechos y exige justicia $>$. Llegar al Zócalo, y más aún, tomarlo y acampar en él, se ha convertido desde hace tiempo en la consigna a seguir por los grupos de manifestantes que pretenden así visibilizarse ante la opinión pública y tener el mayor eco posible ${ }^{10}$, como ocurrió con la caravana zapatista el 11 de marzo de 2001. Circunstancia por la que el Estado a veces hace uso de su derecho al ejercicio de la fuerza para impedir o reprimir ciertas iniciativas, como la manifestación de maestros en defensa de sus derechos, que motivó tener cercado el Zócalo y parte de las calles del Centro Histórico por la policía federal y los militares, desde el 13 de septiembre de 2013 que fueron desalojados, hasta el 16 de octubre que finalmente se levantó para celebrar la ya tradicional Feria Internacional del Libro. Grandes grupos de obreros o campesinos siguen llegando, no obstante, a la ciudad, desde distintos puntos del país, para asentarse temporalmente con cierta facilidad en él, o en su defecto en alguna otra plaza autorizada, y desplegar allí los toldos de plástico para hacer vida por tiempo indeterminado, en un ejercicio de protesta que, independientemente de lo que finalmente se consiga, sirve para liberar tensión y facilitar la catarsis colectiva. "Fuimos desalojados del Zócalo pero mantenemos la lucha y aquí seguimos (asentados ahora en plaza de la Revolución) [...] pasamos necesidades, alejados de nuestros hogares, pero nos sentimos unidos y no nos iremos hasta conseguir que Peña Nieto impulse la reforma educativa y laboral que reivindicamos", dice Luis, organizador estudiantil y activista del Partido Revolucionario de los Trabajadores (PRT), con motivo de la huelga y manifestación de maestros a la que hemos hecho referencia.

Llama la atención, en cualquier caso, la capacidad transformadora del espacio que en cuestión de horas cambia su aspecto y su función: el 27 de octubre de 2013, tras varios intentos fallidos para celebrar asambleas en defensa del petróleo nacional, contra su privatización junto al gas natural, se logró celebrar en el Zócalo un mitin multitudinario contra la reforma energética y el alza de los impuestos pretendida por el Presidente Enrique Peña Nieto (foto 1), con la participación estelar de Andrés Manuel López Obrador, líder del Movimiento de Regeneración Nacional (MORENA). Acto seguido, concluido el mitin que reunió a decenas de miles de personas con pancartas, mientras unos equipos de operarios desmontaban el escenario, tribuna, megafonía, sillas, vallas, etc., otros equipos comenzaban a montar grandes figuras alegóricas y la ambientación propia para el día de Muertos (foto 2) que habría de celebrar en las próximas fechas. Pasado lo cual, ya a finales de noviembre, se comenzaría a levantar un enorme árbol de navidad. Y así sucesivamente.

10 Tal circunstancia ocurre en muchas ciudades modernas; las manifestaciones populares suelen concluir en las grandes plazas y de un modo especialmente significativo en la que nos ocupa. Como recoge Cruces (1998; cfr. Velasco, 2007: 416): “Cuando entras al Zócalo -decía un informante- ¡puuuta!, ¡ya ganaste!”. 


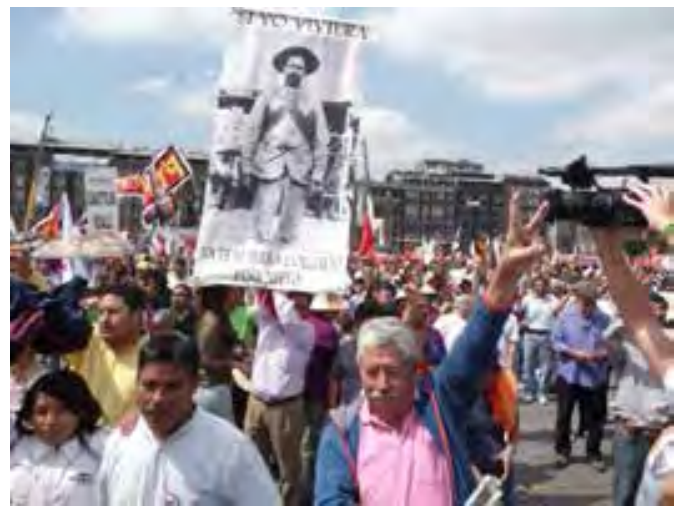

Foto 1: Manifestación ciudadana en el Zócalo contra la reforma energética del Gobierno. 11:00 h, 27 de octubre de 2013.

Con ello entramos en otra de las grandes funciones desempeñadas en la plaza: <<el desarrollo de relaciones sociales, de manifestaciones artísticas, culturales, de esparcimiento y empleo del tiempo libre >>. "Cuando tengo planes, o estoy elucubrando algo, o quiero descansar, o tengo algo que festejar, quién sabe cómo, pero siempre termino dando vueltas en el Zócalo”, dice el músico de jazz Héctor Infazón (Ruvalcava, 2008). Semejante testimonio encontramos en bastantes personas que lo visitan con regularidad, "algo tiene que atrae", nos decían. El asta bandera constituye un recurrido punto de encuentro, bien localizado y despejado, no tiene pérdida, y muchos son los que allí se citan, apreciándose a veces curiosas filas de individuos que aprovechan la larga y estrecha línea de sombra que proyecta el mástil, en la gran explanada desprotegida del sol. Lugar, pues, para quedar, para pasear, conversar en compañía de alguien, pensar en solitario, volar papalotes (cometas), contemplar actuaciones de break dance, de teatro en la calle, de danza de concheros, o ser partícipes de ellas. Lugar que alberga variados acontecimientos culturales durante todo el año, unos eventuales y otros institucionalizados, como el Festival Cultural, presente desde 1985, con música popular, baile libre, conciertos de música clásica, proyecciones de cine, etc.; la Feria Internacional del Libro (FIL) que entre el 16 y el 25 de octubre de 2013 celebró su XIII edición, con la asistencia de 800.000 personas que disfrutaron de 205 actividades, entre presentaciones literarias, charlas, tertulias, sesiones de cuentacuentos, talleres, además de la compra de libros $^{11}$; o el Día de Muertos cada primero de noviembre, con una impresionante puesta en escena en 2013, que incluía espectáculos desde las 15:00 horas hasta la madrugada, y exposiciones de altares con representantes de cada uno de los Estados del país.

La Catedral, allí situada, constituye todo un símbolo al ser la mayor y más antigua de América Latina. La reja de hierro que separa su prolongado atrio delantero de la glorieta circulatoria y la plaza propiamente dicha, como señala Wildner (2005: 126), pareciera trazar una frontera entre lo profano y lo sagrado, o, de otro modo, entre la iglesia y el estado. Pero, más allá de su imponente y destacada presencia, que da idea del peso específico del catolicismo en México, la plaza funciona abiertamente como un <<escenario expresivo de libertad crítica y diversidad religiosa $\gg$. A diario podemos observar cómo hombres y mujeres de distintas confesiones religiosas: católicos, evangélicos, pentecostales, etc., en solitario o acompañados de alguien, en tono generalmente fanático, megáfono en mano, repiten una y otra vez durante horas una larga retahíla aprendida, que invita a los puros a la salvación, amenaza a los pecadores con el fuego eterno del infierno, e interpretan de manera

11 http://www.informador.com.mx/cultura/2013/493484/6/concluye-la-fil-en-el-zocalo-de-mexico.htm (Accedido el 27de febrero 2014). 


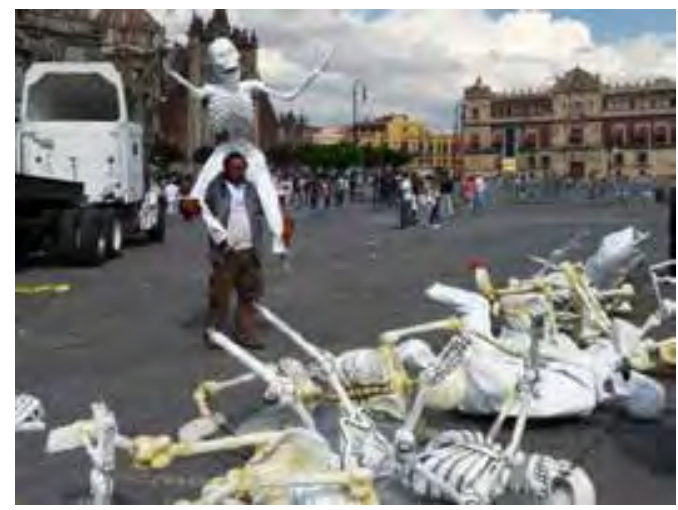

Foto 2: Preparación del Zócalo para el Día de Muertos. 14:00 h. 27 de octubre de 2013.

sui géneris en clave apocalíptica algunos episodios cotidianos. A pocos metros de algunos de estos predicadores, al final de la calle Madero y con la Catedral de fondo tiene su sitio la conocida Julia, disfrazada unas veces de obispo, otras de monja, de fraile, o de sumo pontífice, junto a su acompañante que canta al ritmo de su guitarra y vende los CD con canciones anticlericales que ellos mismo graban, ambos abominan de la iglesia con gestos obscenos (cortes de manga, peinetas, etc.), denunciando que se trata de "una guarida de lobos que devoran a sus corderos", que "los curas son unos violadores y las pinches monjas unas abortistas". Así generan un espacio para ateos, agnósticos o descontentos con la iglesia católica, con quienes continuamente conversan para intercambiar impresiones y sobre todo para que Julia transmita la suya, contando casos de supuestos abusos y engaños por parte del clero, en donde se encuentra ella misma como víctima. Con frecuencia también se dejan ver y oír por allí a los pintorescos Hare Chrishna, con sus inconfundibles cánticos y atuendos color azafrán, que organizados en grupo, bailan y saltan mientras caminan, repartiendo sonrisas, panfletos; procurando recaudar algún dinero con la venta de libros, así como convencer a algunos para que se unan a ellos.

Por supuesto no pasan desapercibidas las videntes o adivinas que con aire seguro, bien sea a través de la lectura de manos o por las cartas, interpretan el pasado y se aventuran a pronosticar el futuro de las personas que, por unos pocos pesos, se sientan con ellas, deseosas de ver cómo les va a ir en la salud, el trabajo, la fortuna o el amor. "Necesita el cariño de los demás y le gusta que le admiren. Es muy exigente consigo mismo. Es algo tímido pero tiene carácter. Tiene capacidades que todavía no ha desarrollado en su beneficio, [...]", me decía una vidente, interpretando las líneas de mi mano.

Y, claro está, en una plaza interétnica y multicultural no podría faltar lo que más arraigado está al pasado histórico del lugar: los chamanes que, ataviados al estilo maya o azteca, aplican sus remedios medicinales, impregnando con el humo del copal el cuerpo de las numerosas personas que van pasando una a una, y con frecuencia forman largas filas esperando su turno para ser atendidas por quienes son dignos de su confianza, a cambio de tan solo la voluntad. "Me voy a hacer una limpia para evitar las malas vibras, nunca se sabe si alguien habla mal o la mira mal a una", decía una joven de unos 25 años, mientras aguardaba que llegara su vez. Lugar de limpia espiritual por tanto, que se suma a todo lo demás completando un escenario en donde el fenómeno religioso se halla muy presente.

Por otro lado, como todo lugar que concentra gran afluencia de público, el $<<$ desempeño de actividades económicas $>>$ está asegurado. Lugar de trabajo para muchos que ofrecen sus servicios, especialmente comerciales, como ya indicamos páginas atrás, y así se ganan la vida. Junto al permanente y molesto ruido provocado por el tráfico rodado, las cansinas y repetitivas retahílas de los predicadores, y la más agradable música producida en algunos 
puntos concretos por grupos de break o de concheros, los mensajes de la venta ambulante para poner en valor las mercancías o servicios ofrecidos carga de animación y vida el ambiente, en una mezcla sinfónica de sonidos que van cambiando de tipo e intensidad según por donde caminemos: "Gomillas para el pelo te valen 10 pesos". "Se acaba el remanente, se acaba el regalo". "A 10, a 10, a 10 varos". "Te vale de a 5, de a 5 te vale, oiga". "Bolsos, bolsos, bolsos a 25". "Se vale 25, se vale 25, pura novedad bonita". "Pura gorra de moda, pura gorra de moda guei". "Bolsa de moda, bolsa de moda guera". "Bolsa de categoría gente, vale a 20, se da a 10 gente". "Te vale 20 varos, 20 pesos, pura chalina fina, gente". "Crema para quemaduras, para cicatrices, llévela oiga, llévela". "Tacos, tortas, refrescos". "Súbale, súbale, servicio" (ciclotaxista). "Limpia a 10" (boleador).

Puestos de tejidos, calzado, bisutería, comida, bebida, música disco, libros, artesanía, masajistas, organilleros, boleadores, ciclotaxistas, etc., se concentran sobre todo en la zona norte frente a la Catedral y junto al Templo Mayor, lugar de mayor afluencia de gente; al igual que en los soportales del Portal de Mercaderes, en el lado oeste, repleto de joyerías de principio a fin.

Lugar igualmente usado para la búsqueda de empleo, como se puede apreciar por la larga fila de 20 o 30 profesionistas sentados junto a la reja de la Catedral por su lado oeste con un cartel que indica la especialidad: plomero, soldador, encofrador, electricista, fontanero, albañil, yesero, carpintero, jornalero, etc. "No es fácil trabajar así, pero que más, [...] la gente sabe que aquí puede encontrar el profesionista que busca para arreglar su cosa y toca esperar", comentaba Diego, albañil de unos 45 años.

Lugar también para hacer efectiva y pública las muestras de solidaridad ciudadana, al instalarse allí, cuando la ocasión lo requiere, un centro de acopio de víveres, ropa y medicina para los damnificados de desastres naturales, afectados por lluvias, inundaciones, tsunamis, terremotos, etc., como ya ha ocurrido repetidas veces. "Este es el mejor sitio para pedir ayuda porque es muy conocido en el DF, [...] la gente sabe dónde estamos y viene a dar lo que puede", aseguraba una de las mujeres responsable del centro de acopio instalado en el Zócalo para las familias damnificadas por los desastres naturales de 2013.

Visto en conjunto, por la gran cantidad y diversidad de gente que discurre por él, y las escasas situaciones conflictivas que se producen, podemos apreciarlo como un $<<$ espacio de tolerancia y encuentro interétnico y multicultural $>>$, por tal motivo atrayente, con piedras cargadas de historia y humanidad; aunque ello no impide que la picaresca y los picaros se den también cita allí, como parte de esa humanidad que nos persuade y previene. "Tenga cuidado, lleva la mochila abierta"(1) - "ahí, gracias señora"(2) "mejor llevarla por delante, con los cacos nunca se sabe"(1), conversaban una vendedora de pañuelos de cuello (1) y una transeúnte (2) que miraba los puestos de venta.

De acuerdo con la idea de Mauss (1979 [1950]) de abarcar las realidades en su totalidad, uno de los conceptos más útiles para entender el Zócalo desde el punto de vista sociocultural, es sin duda el de "hecho social total", desarrollado por el citado autor. Concepto que aplicado a realidades concretas para su comprensión, involucra aspectos económicos, políticos, morales, éticos y estéticos. La célebre expresión remite además a otra estrechamente relacionada con ella: la de "hombre total", que implica la interconexión de lo fisiológico (el cuerpo), lo psicológico (la conciencia individual) y lo social (la conciencia colectiva). Niveles inseparables de análisis que ponen de manifiesto la necesidad de entrecruzar la dimensión colectiva con la individual en el estudio del comportamiento humano, para responder a ¿cuánto hay de social en el pensamiento y la práctica individual?. Teniendo en cuenta el carácter simbólico que tiene lo social en el pensamiento de Mauss, en la medida que los individuos interiorizan los sentidos construidos por la sociedad sobre hechos concretos, a lo que suman la propia experiencia de los mismos, el Zócalo, como hemos visto, genera múltiples expectativas en las personas que ocasional o permanentemente lo ocupan, en función de cómo sea percibido y de lo que para cada cual signifique, provocando reacciones diversas. 
Por todo lo dicho hasta aquí y en línea con lo anterior, el Zócalo de la ciudad de México podemos afirmar que se trata de un $<<$ espacio social total $>>$, un espacio público de encuentro, de socialización, de alteridad e identidad, de simbiosis, un espacio de todos y para todos. Un espacio en el que desde su inicio las autoridades se ocuparon de hacer visibles los tres poderes fundamentales: el político o gubernamental, el religioso o eclesiástico y el económico o mercantil, con la sociedad en el centro. Una sociedad que lo ha hecho suyo, y empoderada en él muestra su propia visión de lo político, más allá de lo que se dicte desde el Palacio Nacional; de lo religioso, diversificando los discursos sin complejos, por muy imponente que sea la presencia de la Catedral; y de lo económico, ampliando la oferta a un público más popular fuera del Portal de Mercaderes. Un espacio convertido en macro escenario de representación social, donde hay que llegar para hacerse ver y escuchar, donde contrastar los puntos de vista, donde la afirmación de la identidad nacional no está reñida con el reconocimiento y respeto de la heterogeneidad social y cultural, donde lo múltiple y diverso constituye un valor añadido en el imaginario colectivo, al igual que la mezcla.

Lejos de la impresión que causa formar parte de un auditorio de más de 100.000 personas que asiste a un mitin político dentro de la plaza, o de observarla a distancia desde algún balcón de hotel, repleta de gente el día de la Independencia, con desfile militar incluido, una de las imágenes más impactantes se puede obtener a ciertas horas de la noche cualquier día de la semana, cuando la plaza ha quedado prácticamente vacía y tan solo vemos en la penumbra a unos pocos padres y madres lanzando al aire platillos voladores fosforescentes junto a sus hijos, novios que se besan o personas solitarias que estáticas contemplan y piensan, no sabemos qué. Rodeada de edificios con tanta historia y poder que, ligeramente iluminados parecen custodiarla, situados en el centro de sus $46.800 \mathrm{~m}^{2}$, con el mástil ahora sin bandera, sentimos el inmenso potencial que encierra como espejo y respiradero de la ciudad y del país, momentáneamente vacía de contenido para, según convenga, llenarse de todo con todos.

\section{bibliografícas}

Arantes, A. (1994): “A guerra dos lugares”. Revista do Patrimonio Histórico Artístico Nacional, 23: 190-203.

Arango, O. (2002): "El Zócalo como texto cultural. Un caso de análisis etnográfico semiótico: la entrada triunfal de la caravana zapatista". Cuicuilco, 9 (25):1-31.

Augé, M. (1993): Los no lugares. Espacios de anonimato. Una antropología de la sobremodernidad. Barcelona: Gedisa.

Bonet, A. (2006): “La plaza principal y mayor corazón y alma de la ciudad”, en Marcos, A. eds.: Plaza Mayor, espacio y representación: 3-5. Salamanca: Universidad de Salamanca. [1209-2015]. Disponible en web: http://www.angelmarcos.com/obra.php/ObrasListado/9bd1 9329dfe4c136f3914fd8c3d971b4.

Cruces, F. (1998): “Imágenes de protesta en ciudad de México". Perfiles latinoamericanos, 12: $227-$ 256.

Foucault, M. (1967): “Des espaces autres”. Architecture, Mouvement, Continuité, 5: 46-49.

García Canclini, N. (Coord.) (1998): Cultura y comunicación en la ciudad de México. México: Grijalbo/UAM.

Lacarrieu, M. (2003): "Nuevas Políticas de lugares: recorridos y fronteras entre la utopía y la crisis", en Welch Guerra, M. coord., Buenos Aires, la ciudad en cuestión. Buenos Aires: Editorial Biblos-Fadu.

Lefebvre, H. (1974): La producción de I'espace. Paris: Editorial Anthropos.

Matos, E. (2012): "La Plaza Mayor o Zócalo en tiempos de Tenochtitlan". Arqueología Mexicana XIX (116): 24-27.

Marina, J.A. (2006): "La Plaza Mayor”, en Marcos, E., eds., Plaza Mayor, espacio y representación: 1-3. Salamanca: Universidad de Salamanca. [12-09-2015]. Disponible en web: http:// www.angelmarcos.com/obra.php/ObrasListado/9bd19329dfe4c136f3914fd8c3d971b4. 
Mauss, M. (1979 [1950]): Sociología y Antropología. Madrid: Tecnos.

Neiburg, F. (2003): "El 17 de octubre en Argentina, Espacio y construcción social del carisma", en Rosato, A. y Balbi, F., Representaciones sociales y procesos políticos: 215-246. Buenos Aires: Antropofagia IDES.

Ortega, S. (2013a): "La Plaza Mayor, tres siglos de dominación española", en Km. Cero. Noticias del Centro histórico de la ciudad de México, 55. [15-12-2014]. Disponible en web: http:// www.guiadelcentrohistorico.mx/kmcero/1-el-centro-fondo/la-plaza-mayor-tres-siglosde-dominaci-n-espa-ola.

(2013b): Siglo XIX: De la Plaza de la Constitución al Zócalo”, en Km. Cero. Noticias del Centro histórico de la ciudad de México, 55. [15-12-2014]. Disponible en web: http://www.guiadelcentrohistorico.mx/kmcero/1-el-centro-fondo/siglo-xix-de-la-plaza-de-la-constituci-n-alZ-calo.

Ovejero, F. (2013): Idiotas O Ciudadanos? El 15-M y la teoría de la democracia. Madrid, Montesinos.

Ruvalcava, P. (2008): "Siempre acabo dando vueltas en el Zócalo”, en Infazón, H., Km. Cero. Noticias del Centro histórico de la ciudad de México, 55. [10-12-2014]. Disponible en web: http://www.guiadelcentrohistorico.mx/kmcero/siluetas/siempre-termino-dando-vueltasen-el-z-calo-h-ctor-infanz-n .

Sánchez del Barrio, A. (2006): "La Plaza Mayor. El gran escenario urbano", en Marcos, A., eds., Plaza Mayor, espacio y representación: 5-18. Salamanca: Universidad de Salamanca. [1209-2015]. Disponible en web: http://www.angelmarcos.com/obra.php/ObrasListado/9bd1 9329dfe4c136f3914fd8c3d971b4.

Sánchez Guevara, G. (2009/2010): "La resemantización del espacio cultural de la Plaza Mayor: las imágenes de los textos de historia”. Revista Electrónica Semestral de Estudios Semánticos de la Cultura, 14-15-16: 1-20.

Stavrides, S. (2012): "Squares in Movement". South Atlantic Quarterly, 111(3): 585-596.

Velasco, H. (2007): Cuerpo y espacio. Símbolos y metáforas, representación y expresividad de las culturas. Madrid: Editorial universitaria Ramón Areces.

Wildner, K. (2005): La plaza mayor, ¿centro de la metrópoli? Etnografía del Zócalo de la ciudad de México. México: Universidad Autónoma de México. 